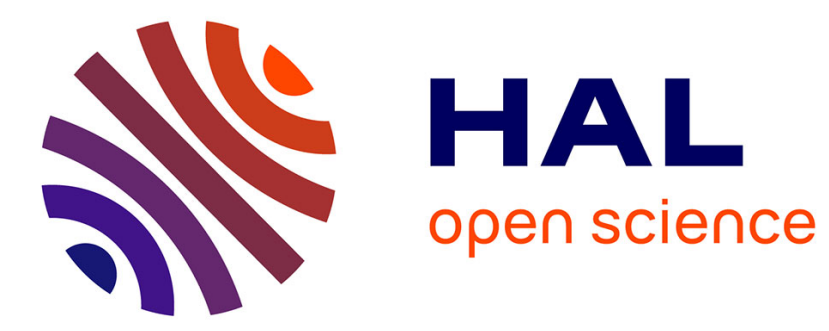

\title{
Solution-oriented versus Novelty-oriented Leadership Instructions: Cognitive Effect on Creative Ideation
}

\author{
Hicham Ezzat, Marine Agogué, Pascal Le Masson, Benoit Weil
}

\section{To cite this version:}

Hicham Ezzat, Marine Agogué, Pascal Le Masson, Benoit Weil. Solution-oriented versus Noveltyoriented Leadership Instructions: Cognitive Effect on Creative Ideation. DCC'16 (Design Computing \& Cognition 2016), Jun 2016, Chicago, United States. halshs-01301511

\section{HAL Id: halshs-01301511 https://shs.hal.science/halshs-01301511}

Submitted on 3 May 2016

HAL is a multi-disciplinary open access archive for the deposit and dissemination of scientific research documents, whether they are published or not. The documents may come from teaching and research institutions in France or abroad, or from public or private research centers.
L'archive ouverte pluridisciplinaire HAL, est destinée au dépôt et à la diffusion de documents scientifiques de niveau recherche, publiés ou non, émanant des établissements d'enseignement et de recherche français ou étrangers, des laboratoires publics ou privés. 


\title{
Solution-oriented versus Novelty-oriented Leadership Instructions: Cognitive Effect on Creative Ideation
}

\author{
Hicham Ezzat ${ }^{1}$, Marine Agogué ${ }^{2}$, Pascal Le Masson ${ }^{1}$, and Benoit Weil ${ }^{1}$ \\ ${ }^{1}$ Mines ParisTech, France ${ }^{2}$ HEC Montréal, Canada
}

The generation of novel ideas is critical to any innovative endeavor. However, one of the key obstacles to creativity is known as the fixation effect, which is the cognitive effect that constrains the generation of novel ideas due to the spontaneous activation of existing knowledge and solutions in individuals' mind. Expert leaders have been considered to play an important role in overcoming these biases using diverse tools. One of these principal instruments is task instruction. Our hypothesis is that leaders' instructions can have significant effects on followers' ideation capacity. We investigated the effect of an instruction given by a leader to his team to generate as many original ideas to a particular creative task, either using solution or novelty-oriented approaches. Results confirmed that solutionoriented instructions activated knowledge bases in fixation, while solutionoriented instructions inhibited these knowledge bases. These results give us new sights into novel models of "less-expert" creative leadership.

\section{Introduction}

Becoming faster, smarter, and increasingly complex, today's world emphasizes the need for creativity and innovation. Recently, survival of organizations became principally linked to the creative generation capacity of their employees. In the past decade, numerous businesses have failed to maintain their position in the innovation flow, and have disappeared from the business scene. These phenomena could be an indication of a lack of creativity in these firms, or perhaps a sign that leaders are unable to benefit from employees' creativeness resources in these organizations.

One possible origin of these blocs to creativity lies principally in a pure cognitive context. Numerous studies in cognitive sciences have highlighted 
the obstructive role of cognitive biases to creativity occurring during ideation processes. One of the most common cognitive bias to creativity is the functional fixedness, also called fixation effect [1], which is the difficulty that individuals are facing during creative contexts, in which they have to solve problems unconventionally.

Many methods like brainstorming, brain writing, and mind mapping (among others) have helped to overcome these cognitive biases to creativity, and increased the creative generation capacity of individuals. Today, these creativity generation methods are endless. Some researchers have even presented a long list of these creativity techniques [2].

Our work highlights the key role that could be played by leaders to stimulate followers' creativity. We examined the cognitive effect of leadership instructions on the creative generation capacity of subordinates during a particular creative task. The instruction given by leaders was to generate the maximum number of original solutions to a certain problem, either using a novelty-oriented search approach or using a solutionoriented search approach. We performed this experiment via a typical creative task where the aim was to propose the maximum number of original solutions to ensure that a hen's egg dropped from a distance of ten meters does not break.

\section{Leadership Definitions}

Leadership has been recognized as one of the most observed and least understood phenomena on earth [3]. It is today extremely difficult to accurately define this term. Indeed, leadership does not have a one-size-fits-all definition. Different explanations describing what leadership is could simply vary from one sector to another (Military, Politics, Education, Sports, etc...). Stodgill concluded that leadership has as many definitions as those who have attempted to define it [4]. Over the past 50 years, scholars and theorists have commonly delineated it into several agreed-upon definition fragments, and have decided to define it widely as a "process of social influence in which a person (the leader) is able to enlist the support of others (his/her subordinates or followers) in the accomplishment of a common task" [5].

Studies on leadership have produced numerous theories involving personality and traits, power and influence, behavior, situations, transactional, transformational, and integrative (among the most cited) [6]. Despite the complexity of precisely delineating leadership study eras throughout the history, several scholars have made the effort to classify the major research 
eras according to the major theories that were developed in each of these periods [6-10].

Notwithstanding the huge historical contributions, progress and development made to the literature of leadership, little focus has been placed around creativity; not because creativity was not a priority, but perhaps because it was directly incorporated in the general notion of efficiency. Until very recently, creativity began to be a subject of serious studies and findings among leadership theorists.

\section{Creativity versus Leadership}

A recent survey made by IBM to more than 1500 large companies' CEOs revealed that the most important leadership quality is creativity [11]. In almost every job, or occupation, there is a place for a certain level of creativity.

Creativity has repetitively been defined as the ability to generate ideas that are both novel and useful, while innovation enlarges the definition of creativity, and involve taking those creative ideas and carrying them through to implementation [12]. Cognitive scientists described it more deeply as a product of many types of intellectual processes that helps setting the stage for creative insights and discoveries [13].

Creative people usually demonstrate a high ideational fluency (which is the aptitude to come up with many new ideas), high degree of novelty, and as well high level of flexibility (known as the ability to stimulate variety among new ideas) [14].

One of today's leadership key roles is to stimulate creativity among subordinates, not only at the individual level, but also at the group and organizational level, by directly or indirectly adapting and manipulating appropriate variables like group climate, group composition, resources, and knowledge management [15].

However, leadership and creativity could be perceived as antagonist concepts, compromised between control and freedom, where too much leadership control kills creativity, and too much freedom leads to chaos. Studies found that a creative leader could be perceived as deviating from the status quo, neglecting interpersonal activities, and not promoting order [13]. Although it can be argued that creativity is unpredictable and cannot be managed in a strict sense, researches proved that creative leaders could control the necessary variables for creativity [16]. 


\section{State of the Art on Creative Leadership}

Literature review of creative leadership has underlined the role played by leaders for creativity [17]. Very early studies on creative leadership underlined the importance of the creativity of leaders themselves, assuming that by being creative, leaders will be having the necessary vision for followers creativity [18].

Prior works have majorly reduced and concentrated leaders' roles as facilitators, mentors, or mediators to organizational creativity [19]. These studies have examined the varied factors that can either foster or hinder employees' creativity at individual, group, and organizational levels, and have subsequently introduced the role of creative leaders.

Other studies on creative leadership were centered especially on the role of leaders' behavior to enhance employees' creativity, i.e. by exploring the direct link between leaders' behavior and creativity. Moreover, studies have also highlighted the role that can be played by leaders to boost employees' creativity by managing external factors like work climate or human resources issues [20]. Deeper studies have analyzed leadership from a creative problem-solving perspective emphasizing the role of leaders to facilitate cognitive processes for more creativity [21], while others even proposed some models of creative leadership [22, 23].

Transformational and transactional leadership are two well-studied styles in creative leadership [24]. Studies made at the transactional era found positive correlations between extrinsic task-motivation (like rewards for example) and employees' creativity. Positive correlations with creativity were as well found during the transformational era, with the introduction among others of the role of emotional intelligence [25], and intrinsic task motivation for creativity [26].

However, these two styles are not mutually exclusive, and many leadership scholars modeled creative leadership as a combination of both transformational and transactional styles to enhance creativity, depending on leaders' cognitive goals structure [27], and their ability to manage their team to reach the goal.

\section{Managing Goals: The Role of Leadership Instructions}

One of the main functions of a creative leader is to stimulate creativity among subordinates, and guide them by appropriately specifying the target goal. Considered a key element in almost all leadership theories, the element "goal" appears very clearly as a basic component of the path-goal theory [28], in which leaders inspire followers to achieve a goal, by guid- 
ing them throughout the process to undertake the appropriate paths leading to the goal.

Traditional leadership styles were pinpointed on the goal component. For instance, transactional leadership is principally based on completing clear and specific goals. When the responsibilities or requirements are successfully completed, transactional leaders give their followers reward in return, yet punish when the followers deviate from the standard.

Moreover, conventional leadership competencies, like planning, organizing, analyzing, goal setting are as well focused around the fundamental role of leadership, which is reaching a specific desired target that a leader envisions and plans to achieve. In this regard, goal could be considered as an organizational desired end-point in some kind of expected organization development.

Among the long list of leadership tools to appropriately set and manipulate goals, there is no doubt that instructions maintain a central and key position. In different studies, studying and experimenting the effects of particular goals have been implicitly modeled, represented and tested through instructions. Even though most studies in creativity consider leaderless groups, there is always an instructor (or experimenter) that clarifies task objectives (and sometimes expectations), by instructing participants what to do at the beginning of the task, or even within the task.

\section{Problematic: A Highly Expert and Knowledgeable Leadership}

Setting and managing task goals is one of the critical roles of leaders. Not only leaders should be competent enough to support their followers in achieving the goal, but also capable of clarifying the paths towards reaching it. Moreover, according to path-goal theory of leadership, an efficient leader is even able to ensure that his followers are attaining the goal, by removing all obstacles and difficulties that are preventing them from reaching it [28].

There is no doubt that all these facts assume a standard of leadership with high levels of task-domain knowledge and expertise, which is not the case in most circumstances. In certain cases, if leaders are not enough expert, they could mislead their team in wrong directions.

In this research, we were interested to study a case where leaders are less expert and less knowledgeable, but even though capable of giving their followers appropriate task instructions, in order to reach creative solutions to problems.

Our research problem includes the following questions: could leaders increase subordinates' ideation capacity without necessary having strong 
task-domain expertise and knowledge? In other words, what type of instructions could leaders give to their team to guide their ideation processes towards creativity, with the minimum level of task-domain expertise and knowledge?

To answer these questions, i) we analyzed the literature review of the impact of instructions on creative ideation, and derived the associated implicit model of leadership; ii) we proposed a model of leadership instructions, and its hypotheses; iii) we presented the theory-driven experiment to test our theoretical predictions; iv) we analyzed the obtained results; v) we ended with the conclusion and limitations of our study.

\section{Literature Review: Impact of Instructions on Creative Ideation}

Ideation has been considered a fundamental process for creative idea generation. Many scholars considered that facilitating the generation of a large number of ideas should lead to creativity. For these reasons, much attention has been given to the different factors contributing to facilitate it.

Many studies in cognitive science have highlighted the close relationship existing between instructions and creative idea generation. Several researchers found that the highest creativity scores in a group occurred when individuals simply had a "creativity goal" instructed and worked alone under expected evaluation [29,30]. More studies have affirmed that when individuals are instructed that creativity is important as a goal, they are more likely to be creative. However, instructing that creativity is important as a goal is essential but not enough to overcome the cognitive biases occurring in creative contexts.

Studies found that instructional factors can highly influence the outcome of the creative problem-solving effort, in a way that is consistent and coherent with the instructions [31]. In these studies, the type of instructions had a differential effect on the different evaluation norms (fluency, flexibility, originality) of creative solutions [29, 32]. When participants were instructed with flexibility-oriented instructions, they generated more different ideas than when instructed with originality-oriented instructions. However, originality rates decreased when given flexibility instructions.

More deeply, Runco et al. tested several types of instructions on creative ideation, and found that procedural instructions are better in terms of fluency, flexibility and originality than conceptual instructions [33]. The level of explicitness of instructions provided for problem solvers influenced the creativity of solutions generated. The more ambiguous instructions were, the more novel and unique generated ideas and solutions were [34]. 
Furthermore, latest studies conducted in interdisciplinary frameworks mixing cognitive sciences with management sciences have helped to clarify the nature of these cognitive biases to creativity, and have been able to identify some type of examples that could be instructed to individuals to overcome fixation effects. One of the principal result in this field is the positive effect of expansive examples on the creative ideation capacity of individuals, while the negative effect of restrictive examples on their creativity [35].

\section{Model of Leadership derived from Literature Review}

Despite the contributions made to the literature on the effects of instructions on creativity, and the indisputable importance of studying instructions' effects on ideation in terms of fluency, flexibility and originality; little is known about the profile of the instructor, his expertise and his knowledge.

The above-mentioned literature review describes an implicit model of instructors that are having high levels of task-domain knowledge and expertise. If we analyze it from a leadership perspective, in order to increase the creative generative capacity in ideation tasks, literature review assumes that the leader should have the following task-domain expertise and knowledge:

- Having high level of task-domain expertise to give procedural instructions to his team to complete tasks in a stepwise manner.

- Having high level of task-domain expertise to transform an explicit instruction into a more ambiguous and implicit one.

- Having high level of task-domain knowledge to stimulate his team with appropriate expansive examples, i.e. an idea that is in expansion (outside the fixation zone).

In consistence with the dominant design of creative leadership presented earlier, being able to give stimulating instructions for creativity generation requires leaders having high levels of expertise and knowledge about the task.

In this study, our motivation was to model instructions that do not necessary require very high levels of expertise and knowledge from the instructor. We assumed in this study, that in order to be able to guide their team in potential directions towards creativity, leaders should have at least the ability to identify the dominant design of the task, i.e. the principal categories of ideas and solutions supposed inside the fixation effect zone.

Based on C-K theory, we were interested to model leadership instructions from a cognitive perspective within an ideation context, in which initial instructions could guide ideation paths to certain types of ideas and so- 
lutions, whether they are restrictive, i.e. do not change object's definition or attributes, or whether they are expansive, i.e. transform object's definition and identity [35]. This cognitive perspective could be more beneficial, as it would provide us with more details on cognitive biases such as fixation effects.

\section{Modeling Leadership Instructions using Design Theories}

In the field of design science, several theories like TRIZ [36], ASIT, SCAMPER, have helped to stimulate creativity in industrial contexts. More recently, C-K theory [37], and KCP method [38] emerged not only as a design theory, but moreover as a theory of cognitive reasoning to bypass cognitive biases' effects occurring in design contexts.

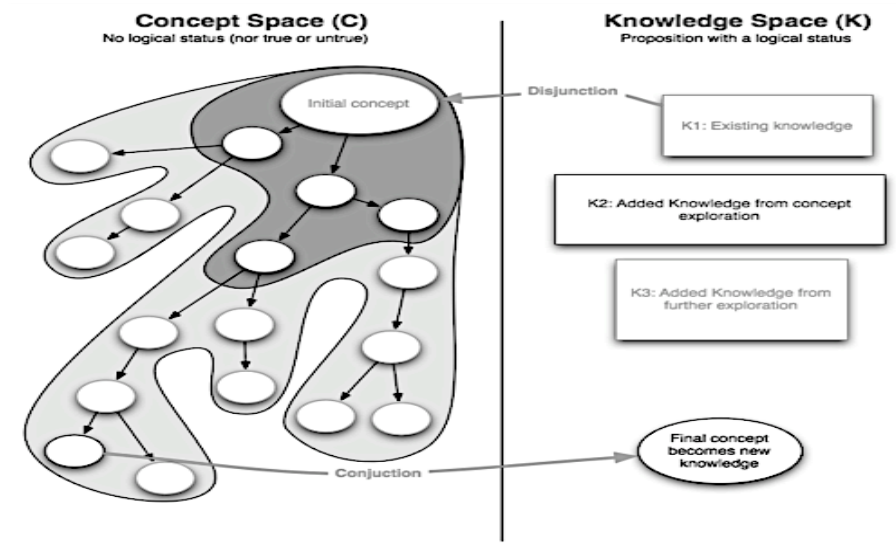

Fig. 1 C-K Diagram

Concept-Knowledge theory's helps overcome cognitive biases' effects occurring in creative design contexts. C-K theory defines two spaces: a space of concepts (labeled "C") and a space of knowledge (labeled "K"). The process of design is defined as a double expansion of both $\mathrm{C}$ and $\mathrm{K}$ spaces, via four operators [39] (as shown in Figure 1):

- $\mathrm{C} \rightarrow \mathrm{K}$ : this operator is called "conjunction". It seeks for added (or subtracted) properties in K space to reach propositions having a logical status (true or false).

- $\mathrm{K} \rightarrow \mathrm{C}$ : this operator is called "disjunction". It adds (or subtracts) some properties coming from $\mathrm{K}$ space to form new concepts having no logical status.

- $\mathrm{C} \rightarrow \mathrm{C}$ : this operator expands the $\mathrm{C}$ space by adding a new partition to it. This new partition can be "restrictive" if it does not change object's 
definition or attributes, or "expansive" if it transforms object's definition and identity by adding (or removing) unexpected attributes.

- $\mathrm{K} \rightarrow \mathrm{K}$ : this operator expands the $\mathrm{K}$ space by adding new knowledge bases to it, and indicates the knowledge structure created within the design concept.

Using this theory, we could model two types of instructions, based on their cognitive effect on the knowledge space:

- Instructions (type A) that would force individuals' cognitive reasoning in $\mathrm{K}$ space to stimulate/activate the known and existing knowledge bases (related to fixation), and to inhibit/deactivate novel knowledge bases (unrelated to fixation).

- Instructions (type B) that would force individual's cognitive reasoning in $\mathrm{K}$ space to inhibit/deactivate known knowledge bases (related to fixation), and stimulate/activate novel knowledge bases (unrelated to fixation).

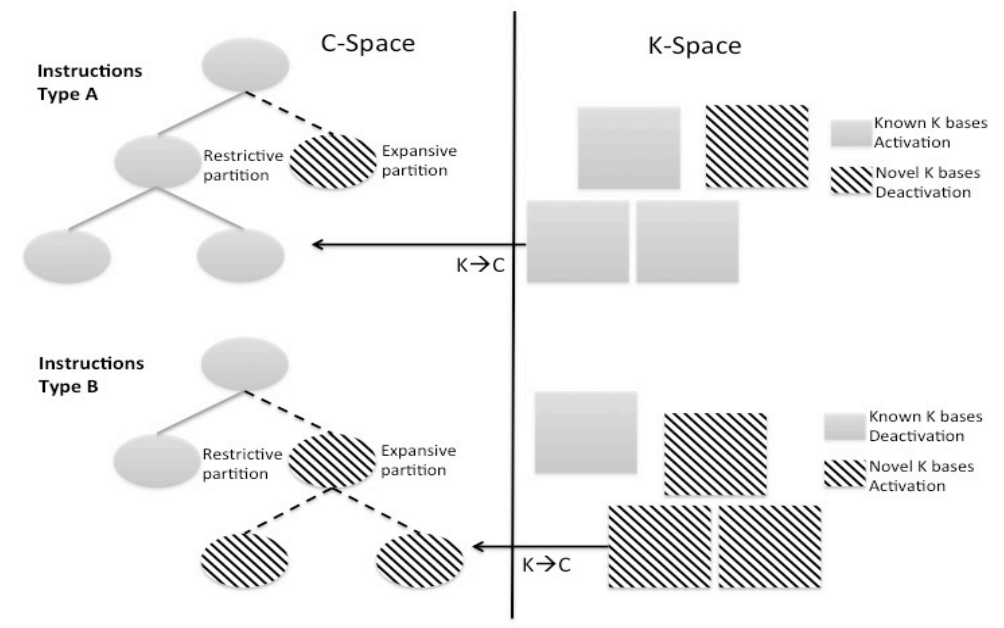

Fig. 2 Modeling Instructions using C-K Theory

As illustrated in Figure 2, these two types of instructions could have different impact on the generation of new concepts in $\mathrm{C}$ space, by disjunction of activated knowledge bases coming from $\mathrm{K}$ space.

On the one hand, we hypothesized that if leaders' instruction indicates that an expected evaluation of testability would be made, this should force subordinates to search for ideas that solve problem-solving tasks in obvious and conventional ways. In other words, knowing that generated ideas must successfully work, individuals will tend to activate already existing knowledge bases, and inhibit novel ones. We then called instructions type A: "solution-oriented". 
On the other hand, we hypothesized that if leaders' instruction indicates that an expected evaluation of novelty would be made (by restricting the dominant design, i.e. categories of ideas related to fixation), this should force subordinates to generate ideas that respond to problem-solving tasks in non-obvious and unconventional ways. In this case, individuals will tend to inhibit already existing knowledge bases, and activate novel ones. We then called instructions type B: "novelty-oriented".

Table 1 Solution versus Novelty-oriented Leadership Instructions

\begin{tabular}{|l|l|l|l|}
\hline $\begin{array}{l}\text { Instruction } \\
\text { Type }\end{array}$ & $\begin{array}{l}\text { Leadership } \\
\text { Expected } \\
\text { Evaluation }\end{array}$ & $\begin{array}{l}\text { Subordinates } \\
\text { Expected } \\
\text { Search } \\
\text { Approach }\end{array}$ & $\begin{array}{l}\text { Expected } \\
\text { Cognitive Effect } \\
\text { on Knowledge Space }\end{array}$ \\
\hline $\begin{array}{l}\text { Solution- } \\
\text { oriented }\end{array}$ & $\begin{array}{l}\text { Ideas will be tested } \\
\text { experimentally }\end{array}$ & $\begin{array}{l}\text { Obvious } \\
\text { Conventional }\end{array}$ & $\begin{array}{l}\text { Stimulation of Existing } \\
\text { Knowledge bases } \\
\text { Inhibition of Novel } \\
\text { Knowledge bases }\end{array}$ \\
\hline $\begin{array}{l}\text { Novelty- } \\
\text { oriented }\end{array}$ & $\begin{array}{l}\text { Ideas must be dif- } \\
\text { ferent from an ex- } \\
\text { isting set of catego- } \\
\text { ries of ideas }\end{array}$ & $\begin{array}{l}\text { Non-obvious } \\
\text { Unconventional }\end{array}$ & $\begin{array}{l}\text { Stimulation of Novel } \\
\text { Knowledge bases } \\
\text { Inhibition of Existing } \\
\text { Knowledge bases }\end{array}$ \\
\hline
\end{tabular}

Table 1 illustrates these solution-oriented and novelty-oriented leadership instructions in terms of expected search approaches (how these instructions would approach the problem), and the expected cognitive effect on the knowledge space of C-K theory (what knowledge bases are expected to be activated/deactivated).

\section{Methods}

\section{Participants}

Participants (N=54) of the course "Products Design and Innovation" have participated in this study. The experiment was made during the first day of the course. Participants were engineering students and professionals working in innovative fields. Subjects were between 20 and 43 years old, with a mean age of 24,4 . Only two participants informed us having already done this creativity task previously in other creative design courses. 


\section{Procedure}

We chose to perform our experiment on the classical hen's egg task where the aim was to propose the maximum number of original solutions to ensure that a hen's egg dropped from a distance of ten meters does not break. We selected this special creativity task among others since we have a vast existing database of ideas and solutions of more than thousands subjects having different profiles (students, engineers, designers, etc...) that performed this task within the past years.

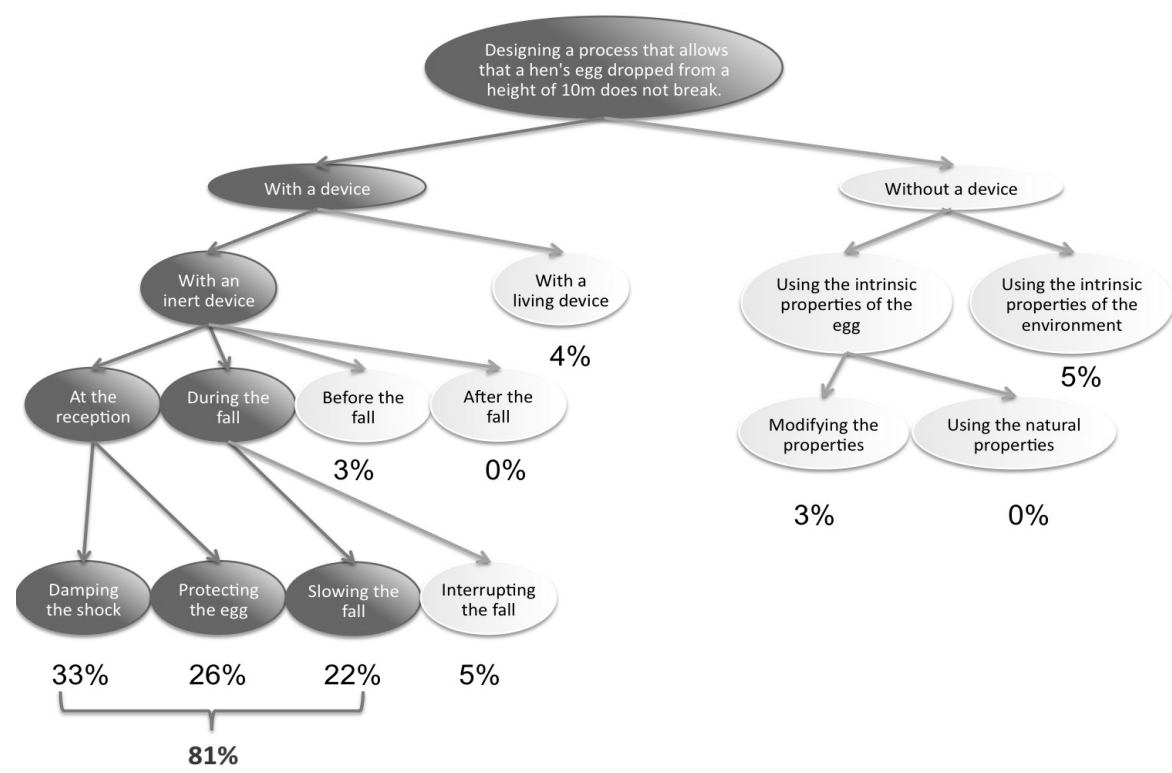

Fig. 3 Using C-Space Tree to determine Fixation in the Egg's Task [35]

As presented in the C-Space tree in Figure 3, our database indicates that more than $80 \%$ of previous subjects generated ideas around three main categories of "restrictive" solutions (which are damping the shock, slowing the fall, and protecting the egg). This enabled us to identify the dominant design of the task as being focused on the "fragility of the egg". However, less than $20 \%$ of subjects were able to generate "expansive" solutions (for instance: before and after the fall, with a living device, using the intrinsic properties of the environment, etc.).

Participants were randomly divided into three groups. Each group had to perform individually the task. Each participant was given a written initial instruction depending on the group he/she belonged to, as illustrated in Table 2. 
Table 2 Leadership instructions given to participants

\begin{tabular}{|l|l|}
\hline \multicolumn{1}{|c|}{ Groups } & \multicolumn{1}{c|}{ Leadership Instructions } \\
\hline $\begin{array}{l}\text { Group 1: } \\
\text { Control }\end{array}$ & $\begin{array}{l}\text { You are a designer and your manager gives you the following } \\
\text { problem: Ensure that a hen's egg dropped from a height of 10m } \\
\text { does not break. } \\
\text { The evaluation of your manager will be based on the number of } \\
\text { original ideas you will propose. }\end{array}$ \\
\hline $\begin{array}{l}\text { Group 2: } \\
\text { olution- } \\
\text { oriented } \\
\text { problem: Ensure that a hen's egg dropped from a height of 10m } \\
\text { does not break. } \\
\text { The evaluation of your manager will be based on the number of } \\
\text { original ideas you will propose, knowing that your solutions will } \\
\text { be tested experimentally. }\end{array}$ \\
\hline $\begin{array}{l}\text { You are a designer and your manager gives you the following } \\
\text { Novelty- } \\
\text { oriented } \\
\text { does not break. } \\
\text { The evaluation of your manager will be based on the number of } \\
\text { original ideas you will propose, knowing that your solutions must } \\
\text { not dampen the shock, or slow the fall, or protect the egg. }\end{array}$ \\
\hline
\end{tabular}

Participants of the first group were given the control instruction with the classical creativity objective as usually instructed in all previous experiments (in our database), which expected them to generate as many original solutions as possible to the problem. We considered group 1 as a referential group for studying groups 2 and 3 .

Participants of the second group had to perform exactly the same task, but with a solution-oriented instruction. We expected that this instruction should force the participants to reflect on solutions focused and fixated on the principal element of the task (which is the "fragility of the egg"), knowing that their ideas will be tested and should successfully work.

The third group performed as well the same task, but was having a novelty-oriented instruction forcing them to search for ideas outside the three main categories in fixation zone (all focused on the principal element of the task). Manager expected group 3 to generate ideas and solutions, knowing that they must not belong to the already pre-existing categories of "restrictive" responses.

\section{Results}

Ideation is the process of coming up with alternative solutions to a particular problem. As we have indicated earlier, divergent thinking has been known to consider three main elements for evaluating a creative ideation process, which are the ideational fluency (which refers to the mean number 
of ideas generated by a population), ideational originality (which refers to the frequency of occurrence of the type of idea), and ideational flexibility (which is the number of different groups/categories of ideas generated by individuals).
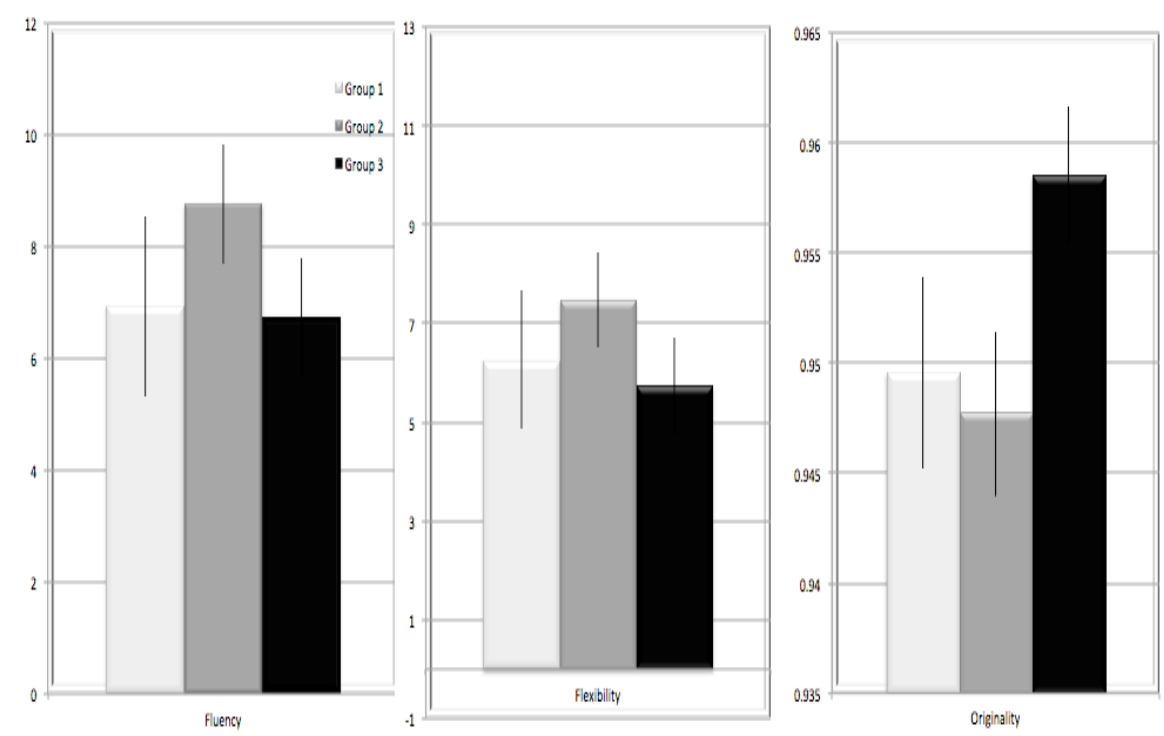

Fig. 4 Statistical analysis of groups' results

In terms of fluency, we computed the mean number of ideas generated by participants of each group, as well as the SEM (Standard Error of the Mean). Results (in Figure 4) showed that participants of the solutionoriented group (group 2) were able to generate more ideas than participants of the novelty-oriented group (group 3), as well as participants of the control group (group 1). Interestingly, participants of group 3 were able to generate a mean number of ideas that is quite similar than group 1 .

In terms of flexibility of solutions, we calculated the mean number of different categories of ideas generated by participants in each group. In this regard, group 2 had the highest score of flexibility, while group 3 had the lowest one. In this regard, SEM values shows that flexibility results are not very significant.

Finally, we analyzed originality of ideas of each group by computing the frequency of solutions given across all the subjects. In this regard, we found that participants of group 3 we able to generate more original and unique solutions than participants of group 2 and group 1.

Nevertheless, analyzing mean number of solutions of each group in terms of fluency/flexibility/originality is not enough in this study. For this 
reason, and in order to have a better view of the effect of instructions on creative ideation, we analyzed the mean number of solutions that groups were able to generate in the fixation zone (restrictive solutions), or in the expansion zone (expansive solutions), as illustrated in Figure 5.
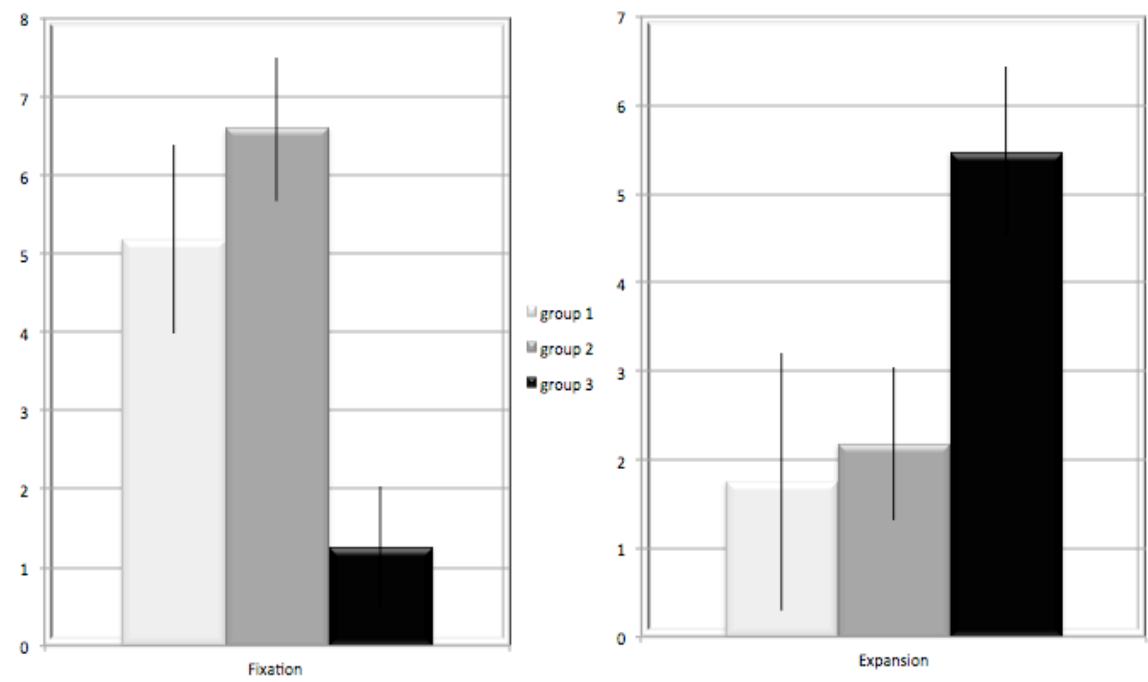

Fig. 5 Mean number of solutions inside and outside Fixation in each group

Results showed that group 2 tended to generate more restrictive ideas and solutions than group 3 and group 1. Contrary to group 2, group 3 tended to generate more expansive ideas and solutions than group 2 and group 1. As shown in Figure 5, the mean number of expansive ideas generated by group 3 is approximately equivalent to the mean number of restrictive ideas generated by the referential group. These results show that noveltyoriented instruction forced the activation of knowledge bases outside fixation, which augmented the number of expansive ideas generated by participants. On the other hand, solution-oriented instruction forced the activation of knowledge bases inside fixation, which increased the number of restrictive ideas generated by participants.

\section{Conclusions and Limitations}

In this study, we explored the effect of two types of leadership instructions on subordinates' creative idea generation capacity during a creative task. The aim of the task was to propose the maximum number of original solutions to ensure that a hen's egg dropped from a distance of ten meters does 
not break. We compared solution-oriented leadership instructions to novelty-oriented leadership instructions.

From a cognitive sciences' perspective, two major findings emerged from this investigation: (i) the group exposed to novelty-oriented instructions was able to generate more original solutions than the group exposed to solution-oriented instructions; (ii) the group exposed to solutionoriented instructions tended to generate more restrictive ideas, while the group exposed to novelty-oriented instructions tended to generate more expansive ideas.

From a managerial perspective, our results show that less expert and knowledgeable leaders (having at least the ability to recognize the task dominant design, i.e. principal categories of restrictive ideas) could play an important role in stimulating followers' creativity.

Future works will consist in testing this novelty-search approach within a more dynamic leader-member interaction, by investigating leadership instructional processes in real-time using feedbacks. This future study could enable exploring new sights in creative leadership behaviors, as well as leaders' capacity to drive the idea generation paths towards fixation or expansion in real-time.

A limitation of our study is that it is far from a real setting involving a leader-member exchange process. Our study could be considered as a building block for further more realistic interdisciplinary leadership studies mixing cognitive sciences with management. These future studies could take into account the complexity of the numerous contextual variables of leadership equation (real contexts with incentives, hierarchy issues for subordinates, specific contextual factors, etc..)

\section{Acknowledgments}

This research was financed by a grant from the French National Research Agency (project ANR-13-SOIN-0004-04 IDéfixE). The authors would like to thank Sophie Hooge for giving us the opportunity to run these experiments during her course "Products Design and Innovation".

\section{References}

1. Jansson, D.G. and S.M. Smith, Design fixation. Design studies, 1991. 12(1): p. 3-11.

2. Kowaltowski, D.C., G. Bianchi, and V.T. De Paiva, Methods that may stimulate creativity and their use in architectural design education. International Journal of Technology and Design Education, 2010. 20(4): p. 453-476.

3. Burns, J.M., Leadership. 1978, New York: Harper \& Row. 
4. Stogdill, R.M., Handbook of leadership: A survey of the literature. 1974, New York: Free Press.

5. Chemers, M., An integrative theory of leadership. 2014: Psychology Press.

6. Van Seters, D.A. and R.H. Field, The evolution of leadership theory. Journal of organizational change management, 1990. 3(3): p. 29-45.

7. Yukl, G.A., Leadership in organizations. 1994: Pearson Education India.

8. Brungardt, C., The making of leaders: A review of the research in leadership development and education. Journal of Leadership \& Organizational Studies, 1997. 3(3): p. 81-95.

9. Bolden, R., et al., A review of leadership theory and competency frameworks. 2003, Centre for Leadership Studies, University of Exeter Exeter.

10. Daft, R., The leadership experience. 2014: Cengage Learning.

11. Carr, A. and S. Tomasco, The most important leadership quality for CEOs? Creativity. Fast Company, 2010(May 18).

12. Amabile, T.M., The social psychology of creativity: A componential conceptualization. Journal of personality and social psychology, 1983. 45(2): p. 357.

13. Mueller, J.S., J.A. Goncalo, and D. Kamdar, Recognizing creative leadership: Can creative idea expression negatively relate to perceptions of leadership potential? Journal of Experimental Social Psychology, 2011. 47(2): p. 494-498.

14. Guilford, J.P., Traits of creativity. Creativity and its cultivation, 1959: p. 142-161.

15. Hemlin, S., C.M. Allwood, and B.R. Martin, Creative knowledge environments. Creativity Research Journal, 2008. 20(2): p. 196-210.

16. Amabile, T. and S.S. Gryskiewicz, Creativity in the R\&D laboratory. 1987: Center for Creative Leadership.

17. Mumford, M.D., et al., Leading creative people: Orchestrating expertise and relationships. The Leadership Quarterly, 2002. 13(6): p. 705-750.

18. Mumford, M.D., S. Connelly, and B. Gaddis, How creative leaders think: Experimental findings and cases. The Leadership Quarterly, 2003. 14(4): p. 411-432.

19. Woodman, R.W., J.E. Sawyer, and R.W. Griffin, Toward a theory of organizational creativity. Academy of management review, 1993. 18(2): p. 293-321.

20. Shalley, C.E. and L.L. Gilson, What leaders need to know: A review of social and contextual factors that can foster or hinder creativity. The Leadership Quarterly, 2004. 15(1): p. 33-53.

21. Reiter-Palmon, R. and J.J. Illies, Leadership and creativity: Understanding leadership from a creative problem-solving perspective. The Leadership Quarterly, 2004. 15(1): p. 55-77.

22. Sternberg, R.J., J.C. Kaufman, and J.E. Pretz, A propulsion model of creative leadership. The Leadership Quarterly, 2003. 14(4): p. 455-473.

23. Rickards, T. and S. Moger, Creative leadership processes in project team development: an alternative to Tuckman's stage model. British Journal of Management, 2000. 11(4): p. 273-283.

24. Jung, D.I., Transformational and transactional leadership and their effects on creativity in groups. Creativity Research Journal, 2001. 13(2): p. 185-195.

25. Zhou, J. and J.M. George, Awakening employee creativity: The role of leader emotional intelligence. The leadership quarterly, 2003 14(4): p. 545-568.

26. Amabile, T.M., Motivating creativity in organizations: On doing what you love and loving what you do. California management review, 1997. 40(1): p. 39-58. 
27. Wofford, J. and V.L. Goodwin, A cognitive interpretation of transactional and transformational leadership theories. The Leadership Quarterly, 1994. 5(2): p. 161-186.

28. House, R.J., A path goal theory of leader effectiveness. Administrative science quarterly, 1971: p. 321-339.

29. Shalley, C.E., Effects of coaction, expected evaluation, and goal setting on creativity and productivity. Academy of Management Journal, 1995. 38(2): p. 483-503.

30. Carson, P.P. and K.D. Carson, Managing Creativity Enhancement Through Goal-Setting and Feedback*. The Journal of Creative Behavior, 1993. 27(1): p. 36-45.

31. Runco, M.A., J.J. Illies, and R. Eisenman, Creativity, originality, and appropriateness: What do explicit instructions tell us about their relationships? The Journal of Creative Behavior, 2005. 39(2): p. 137-148.

32. Runco, M.A. and S. Okuda, The instructional enhancement of the flexibility and originality scores of divergent thinking tests. Applied Cognitive Psychology, 1991. 5(5): p. 435-441.

33. Runco, M.A., J.J. Illies, and R. Reiter-Ralmon, Explicit Instructions to Be Creative and Original. The International Journal of Creativity \& Problem Solving, 2005. 15(1): p. 5-15.

34. Ward, T.B., M.J. Patterson, and C.M. Sifonis, The role of specificity and abstraction in creative idea generation. Creativity Research Journal, 2004. 16(1): p. 1-9.

35. Agogué, M., et al., The Impact of Type of Examples on Originality: Explaining Fixation and Stimulation Effects. The Journal of Creative Behavior, 2014. 48(1): p. 1-12.

36. Al'tšuller, G.S., The innovation algorithm: TRIZ, systematic innovation and technical creativity. 1999: Technical Innovation Center, Inc.

37. Hatchuel, A. and B. Weil. A new approach of innovative Design: an introduction to CK theory. in DS 31: Proceedings of ICED 03, the 14th International Conference on Engineering Design, Stockholm. 2003.

38. Hatchuel, A., P. Le Masson, and B. Weil. Design theory and collective creativity: a theoretical framework to evaluate KCP process. in International conference on engineering design, ICED. 2009.

39. Hatchuel, A. and B. Weil. CK theory. in Proceedings of the Herbert Simon International Conference on «Design Sciences. 2002. Citeseer. 